\title{
System Macromodel of Agricultural Building with Aim to Energy Consumption Minimization
}

Vít Malinovský

Department of System Engineering, Faculty of Economics and Management, Czech University of Life Sciences, Prague, Czech Republic

\begin{abstract}
Economizing on energy intended for heating of agricultural buildings is correlative with their convenient construction from the viewpoint of both thermal and mechanical properties. Therefore, knowledge of temperature time characteristics enables building construction optimizing. This paper deals with process of recognizing elements and parameters of some particular building object, assembling its system macromodel, and analysing temperature time characteristics on its base using appropriate mathematic tools (Laplace and Fourier transformation, matrix characterizing of model parameters) and special software (ANATH). Finally, the resulting temperature time characteristics can be used for an optimal design of some planned agricultural object or for reconstruction of some existing one.
\end{abstract}

\section{Keywords}

Economy of agricultural engineering, heating energy economy, system analysis, temperature time characteristics, expenses optimizing, ambient temperature well-being.

Malinovský, V. (2018) "System Macromodel of Agricultural Building with Aim to Energy Consumption Minimization", AGRIS on-line Papers in Economics and Informatics, Vol. 10, No. 1, pp. 25-35. ISSN 1804-1930. DOI 10.7160/aol.2018.100103.

\section{Introduction}

Nowadays, significance of heating energy economy constantly increases. On that account, it is need to lay enhanced emphasis on building constructions design in consideration of energy consumption minimization. To process the most heat-economic building project possible, system designers must carry out a careful structural analysis from the viewpoint of active zones origin induced by floating temperature differences.

By help of a mathematic model of a building construction, it is possible to simulate and study heat behaviour of each structural element in response to time changes caused by both outdoor temperature and indoor heating system. This method is applicable for indoor non-stationary heat processes analysis as well as for computer-controlled heating optimization. (Mehta and Woods, 1981)

The idea is based on analogy between electronic and heat circuits and, therefore, the rules used for resolving electronic circuits can be analogically used for resolving heat circuits represented by the building construction mathematic model. For easy computer algorhitmizing, characteristics of the time heat responses are "harmonized" by use of the Fourier transformation (Bracewell, 1999). The model environment is described by help of the finite element method with composed parameters (thermal conductivity, thermal capacity, temperature controlled heat flow sources) and elements with spread parameters (where geometric dimensions do not allow to consider insulation resistance and thermal capacity as separate parameters) (Dong et al., 2015).

First time, this method was introduced by Professor Jiří Pánek, the former dean of the Faculty of Civil Engineering at CTU in Prague and, afterwards, it was enhanced by Professor Petr Moos and Associate professor Dalibor Vytlačil, both of them of the same institute. Later (in 1993), senior lecturer Vít Malinovský worked up a method and carried out its application on particular building constructions together with a comparative analysis of the obtained results. At the Department of Building Equipment at CTU, the team led by Professor Miroslav Jokl developed the special application ANATH for analysis and synthesis intended for calculating heat responses at different building structural configurations (Jokl, 1989). 


\section{Materials and methods}

\section{Mathematic model construction}

To be able to perform matrix analysis of heat sources inside a building object, it is necessary to design an appropriate model of a building construction. The first step includes using some applicable tools from the field of system projecting determined for identification an existing or planned system within the real world and, consequently, transforming the identified system into a mathematic model form (Sangi et al., 2016). This form should take into consideration the above mentioned analogy between electronic and heat circuits for physical parameters to be definitely assigned and processed by the analytic software.

\section{Description of model with concentrated elements}

Description of model with concentrated elements deals with characterizing system properties by means of discrete (discontinuous) elements. The method proceeds from analogy between heat and electric current flow. The system consist of the following elements:

a) Thermal resistance is a point through which a heat flow $Q$ passes. The $Q$ heat flow replaces an integral representation with the Laplace image form.

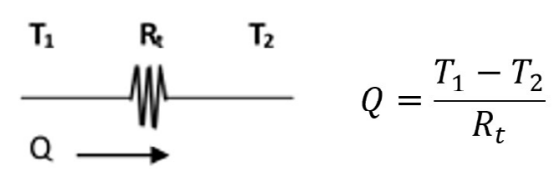

$Q \quad$ heat flow [W];

$T_{1}, T_{2}$ temperatures before and behind a point of resistance $\left[{ }^{\circ} \mathrm{C}\right]$;

$R_{t} \quad$ thermal resistance $\left[\mathrm{W} \cdot \mathrm{m}^{-1} \cdot \mathrm{K}^{-1}\right]$.

b) Thermal capacity is an element simulating the system accumulation properties.

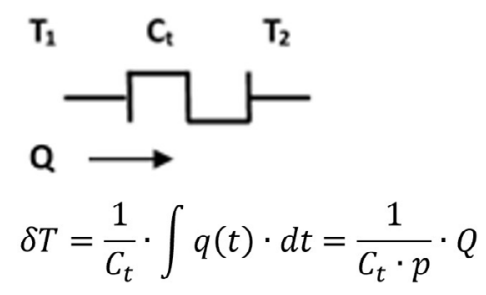

$Q \quad$ heat flow [W];

$T_{1}, T_{2}$ temperatures before and behind a point of resistance $\left[{ }^{\circ} \mathrm{C}\right]$;

$\delta T \quad$ difference of temperatures after heat passing through an element $\left[{ }^{\circ} \mathrm{C}\right]$;

$C_{t} \quad$ thermal capacity $\left[\mathrm{J} \cdot \mathrm{m}^{-1} \cdot \mathrm{K}^{-1}\right]$;

$p \quad$ Laplace operator [-]; $t, d t$ time and time increase [s],

c) Heat flow resource is an element representing a regulated or unregulated heating system.

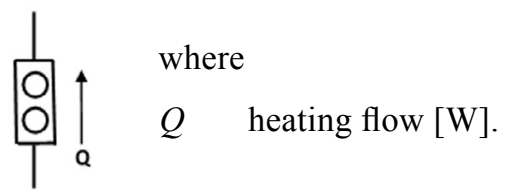

A heat flow resource can be regulated or unregulated. The regulated resource is characterized by the regulation factor $g$ determining a change of temperature by $1{ }^{\circ} \mathrm{K}$ in a point of a sensor (controlling temperature point).

\section{Description of model with spread elements}

Description of model with spread elements solves inaccuracies of the previous description caused by assumption that only condition of all materials predominates (i.e. polystyrene - thermal resistance, concrete and stone - thermal capacity, etc.). However, other conditions of the most of materials cannot be omitted because both heat resistance and thermal capacity are functions of the element's thickness and, that is why, it is not possible to consider each condition separately and compile the result afterwards (Moziraji et al., 2014).

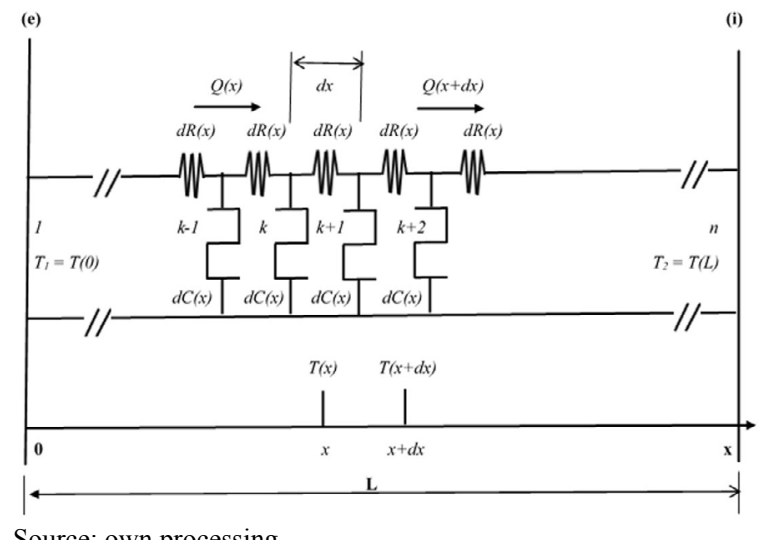

Source: own processing

Figure 1: Scheme of model with spread elements.

$Q \quad$ heat flow [W];

(e), (i) exterior, interior;

$x \quad$ variable of thickness ( $x=0$ outer surface; $x=L$ inner surface) $[\mathrm{m}]$;

$L \quad$ thickness of the whole perimeter construction $[\mathrm{m}]$;

$d R(x)$ increase of thermal resistance within the distance element $\mathrm{dx}\left[\mathrm{W} \cdot \mathrm{m}^{-1} \cdot \mathrm{K}^{-1}\right]$;

$d C(x)$ increase of thermal capacity within the distance element $\mathrm{dx}\left[\mathrm{J} \cdot \mathrm{m}^{-1} \cdot \mathrm{K}^{-1}\right]$;

$T(x)$ temperature in the point $\mathrm{x}\left[{ }^{\circ} \mathrm{C}\right]$;

$Q(x)$ heating flow in the point $\mathrm{x}$ [W]. 


\section{Mathematic definition of model with spread elements}

The relations between quantities characterizing the model with spread elements is based on the following formulas:

$\frac{\sigma T(x, t)}{\sigma x}=R(x) \cdot Q(x, t)$

and

$\frac{\sigma Q(x, t)}{\sigma x}=C(x) \cdot \frac{\sigma T(x, t)}{\sigma t}$

where

$T$ temperature $\left[{ }^{\circ} \mathrm{C}\right]$;

$Q \quad$ heating flow [W];

$R$ thermal resistance $\left[\mathrm{W} \cdot \mathrm{m}^{-1} \cdot \mathrm{K}^{-1}\right.$;

$C$ thermal capacity [J.m-1.K-1];

$x \quad$ position of examined point $[\mathrm{m}]$;

$t$ time [s].

The temperature equation results from deriving the formula (3) and substituting the result into the formula (4).

$$
\begin{aligned}
\frac{\sigma^{2} T(x, t)}{\sigma^{2} x} & -\frac{1}{R(x)} \cdot \frac{\sigma R(x)}{\sigma x} \cdot \frac{\sigma T(x, t)}{\sigma x} \\
& -R(x) \cdot C(x) \cdot \frac{\sigma T(x, t)}{\sigma t}=0
\end{aligned}
$$

The heating flow results again from derivate the formula (3) and substituting the result into the formula (5).

$$
\begin{aligned}
\frac{\sigma^{2} Q(x, t)}{\sigma^{2} x}- & \frac{1}{R(x)} \cdot \frac{\sigma R(x)}{\sigma x} \cdot \frac{\sigma Q(x, t)}{\sigma x} \\
& -R(x) \cdot C(x) \cdot \frac{\sigma Q(x, t)}{\sigma t}=0
\end{aligned}
$$

The formulas (5) and (6) create a matrix differential equation with three variables. The time equation is transformed by means of Laplace transformation to the following form:

$T(x, p)=A_{1} \cdot e^{-\tau x}+A_{2} \cdot e^{-\tau x}$

and

$Q(x, p)=B_{1} \cdot e^{-\tau x}+B_{2} \cdot e^{-\tau x}$

where

$\tau^{2}=p \cdot C_{t} \cdot R_{t}$ heating constant;

$R_{t} \quad$ specific thermal resistance $\left[\mathrm{W} \cdot \mathrm{m}^{-1} \cdot \mathrm{K}^{-1}\right.$;

$C_{t} \quad$ specific thermal capacity $\left[\mathrm{J} \cdot \mathrm{m}^{-1} \cdot \mathrm{K}^{-1}\right]$;

and contains two linearly dependent constants:
$B_{1}=\tau_{0 .} A_{1}$

and

$B_{2}=\tau_{0} \cdot A_{2}$

where the specific heating constant is of the following form:

$\varrho_{0}=\sqrt{\frac{R_{t}}{p \cdot C_{t}}}$

For the model, the boundary conditions are determined: temperature $T_{2}$ on the inner surface $(x=L)$ and heating flow $Q_{2}$, and temperature $T_{1}$ on the outer surface $(x=0)$ and heating flow $Q_{1}$. After substitution of (9), (10), and (11) to the equations (07) and (08) and examining the boundary conditions, the following matrix form arises (Draghici at al., 1998):

$\left[\begin{array}{l}T_{1}(p) \\ Q_{1}(p)\end{array}\right]=\left[\begin{array}{cc}\cosh \tau d & \varrho_{0} \sinh \tau d \\ \frac{1}{\varrho_{0}} \sinh \tau d & \cosh \tau d\end{array}\right] \cdot\left[\begin{array}{l}T_{2}(p) \\ Q_{2}(p)\end{array}\right]$

The middle matrix $[A]$ contains all information on heating change of a layer with $L, C$, and $R$ parameters. For multilayer constructions, the resulting matrix $[A]$ can be obtained by multiplying particular matrixes of individual construction layers from the outer surface to the inner one. For a construction consisting of $n$ layers, the aggregate matrix is of the form (Pöttgen et al., 2016):

$[A]=\left[A_{1}\right] \cdot\left[A_{2}\right] \cdot\left[A_{2}\right] \cdot \ldots \cdot\left[A_{n}\right]$

For computer processing, performing Fourier transformation $(p=j . \Omega)$ is very useful because it can transform time courses to harmonic ones (Sonderegger, 1977).

$\tau^{2}=j \Omega C_{t} R_{t}$ heating constant:

complex unit $\mathrm{j}[-]$; angular frequency

$\Omega\left[\mathrm{s}^{-1}\right]$;

specific thermal resistance related to $1 \mathrm{~m}^{\prime} R_{t}\left[\mathrm{~W} \cdot \mathrm{m}^{-1} \cdot \mathrm{K}^{-1}\right]$;

specific thermal capacity related to $1 \mathrm{~m}^{\prime} C_{t}\left[\mathrm{~J} \cdot \mathrm{m}^{-1} \cdot \mathrm{K}^{-1}\right]$;

$\varrho_{0}=\frac{R_{t}}{j \cdot \Omega \cdot C_{t}}$ specific heating constant;

$\Omega=\frac{2 \Pi}{T}$ angular frequency $\left[\mathrm{s}^{-1}\right]$; period $T[\mathrm{~s}]$;

$\Theta=\Omega C_{t} \cdot R_{t} L^{2}$ heating flow;

thickness of spread parameter $L[\mathrm{~m}]$; total thermal resistance $R_{t} L\left[\mathrm{~W} \mathrm{~K}^{-1}\right]$; total thermal capacity $C_{t} L[\mathrm{~J} \mathrm{~K}-1]$ 
By dividing (12) according to the De Moivre's formula to a real and complex part, the coefficients of the complex matrix $[A]$ arise. The real part describes a module (maximum deviations of heating cycle) while the complex part describes a phase (time delay from exciting change) (Moos, 1989).

\section{Analysis of barn building model}

The following procedure consists of processing expected data of exterior time temperature courses by means of Fourier transformation representing independently variable quantities causing temperature changes inside the building constructions (Stupka et al., 2014). Next, important inner and outer points of around the construction so called thermal nodes - are assigned by unique numerals. These numerals create the building construction heat model including heat relations to the monitored subjects inside the building construction (Wachowicz et al., 2016).

\section{Barn model construction}

First, for easier projection, a simplified barn building 3D-model (see Figure 2) is designed. For this purpose, a single-space building object of three-layer perimeter wall was chosen to represent an initial base for a particular scheme creation (Svoboda, 2012). The spatial projection contains marking of a typical wall cross-section $A-A$ that is shown on the upper part of Figure 2. Also a glass-walled part is taken into the account for temperature changing calculation (Malinovský, 1993).

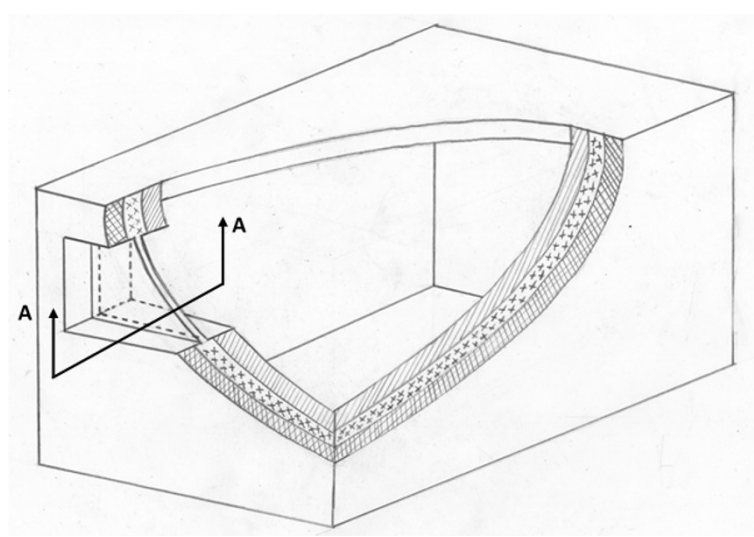

Source: Author's own work

Figure 2: Simplified barn building 3D-model.

This 3D-model allows to create the particular scheme of a thermal circuit (shown on the bottom part of Fig. 2) representing a construction part of the barn building. The thermal circuit is used for entering input parameters for calculation processed by the ANATH application (Zajicek and Kic, 2014).
The ANATH application serves for calculating thermal responses of the system (object model) for changes of the outdoor temperature and, concurrently, for simulating situations when the elements and their parameters affecting the global thermal system behaviour are changing. It results from data containing recorded temperature values in the course of 24 hours. The curves representing temperature courses within the given time unit are not harmonic and are not in accordance with goniometrical functions. However, by help of Fourier transform, these non-harmonic but periodical curves can be replaced by a sum of goniometrical functions (Moos and Vytlačil, 1991):

$T_{i}(\Omega \cdot t)=\left|M_{i}\right| \cdot e^{j \cdot \Phi_{i}}$

where

$M_{i} \quad$ modules of individual harmonic items $\Omega$, $2 \Omega, 3 \Omega \ldots \mathrm{n} \Omega$ (frequency functions);

j complex unit;

$\Phi_{i} \quad$ argument of harmonic item

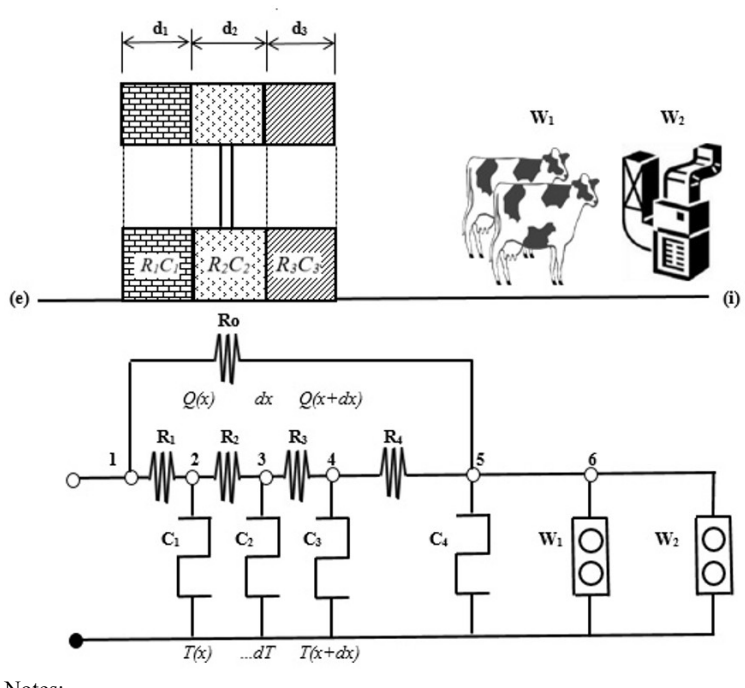

Notes:

$d_{i}$ individual construction layers' thicknesses;

$W_{1}$ unregulated heating source - cattle (Chloupek, 1992);

$W_{2}$ regulated heating source - heating system;

$C_{i} \quad$ individual construction layer thermal capacities;

$R_{i} \quad$ individual construction layer thermal resistances;

$T(x)$ temperature as function of distance $\mathrm{x}\left[{ }^{\circ} \mathrm{C}\right]$;

$Q(x)$ heating flow as function of distance $\mathrm{x}[\mathrm{W}]$ Source:

Figure 3: Barn building heating scheme.

\section{Calculation procedure}

For describing the barn building thermal system, the system matrix equation has to be created. The presence of the heat $q$ within the barn construction is represented predominantly 
in the form of the heating flow $Q$ considered as an agent. For this quantity, the principle of agents conservation states can be expressed as following (Price and Smith, 1995):

$$
\sum_{i=1}^{n} \Delta Q_{i}=0
$$

where

$\Delta Q_{i} \quad$ increases of individual heating flows components inside barn construction.

This equation can be expressed in the developed form:

$$
[Q]-[h] \cdot[T]=0
$$

where

$[Q]$ matrix of external heating flows;

[h] system matrix;

[T] matrix of temperatures in heating nods.

The matrices $[Q],[h]$, and $[T]$ contain Laplace images of the corresponding time functions.

After separating the external heating flows matrix $[Q]$ to the left, the following matrix equation (in full form) origins:

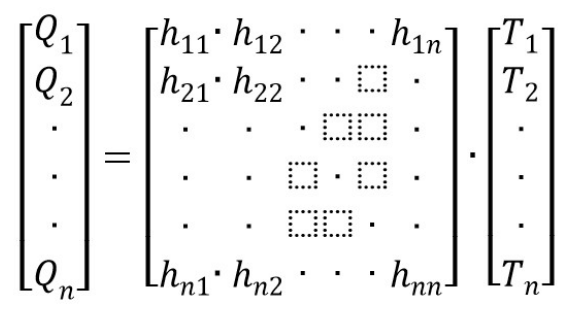

This matrix can be seen as the following scheme representing the construction heating system exposed by the external heating flows $Q_{1}, Q_{2} \ldots Q_{n}$ in the heating nods $T_{1}, T_{2} \ldots T_{n}$.

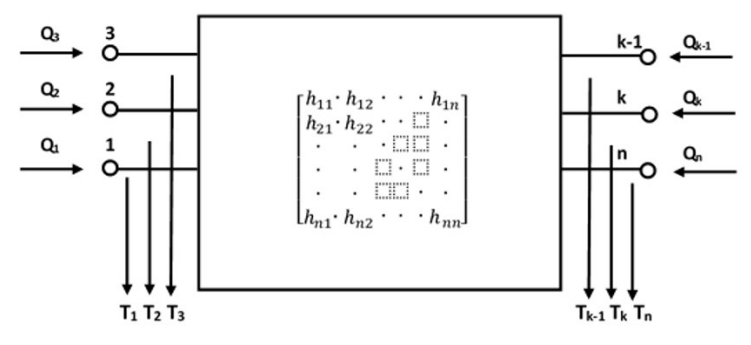

(17B)

The temperature values and their time courses are the most important quantities for state changes examining in the given points and, therefore, the equation (17) must be adjusted so that the heating nods matrix would be in the left side:

$$
[T]-[h]^{-1} \cdot[Q]
$$

or in the full form:

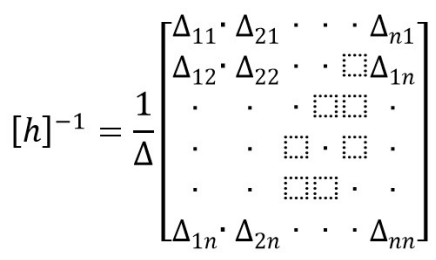

where

$\Delta \quad$ determinant of $[h]$ matrix;

$\Delta_{i j} \quad$ algebraic complements to appropriate $[h]$ matrix elements.

Supposing only exterior represents a source of the heating flow $Q_{1}$ and this environment is characterized by the $T_{1}$ temperature, another heating flows $Q_{2}, Q_{3} \ldots Q_{n}$ are of zero value, nevertheless, inner heating flows within the construction are time dependent values in relation to both $Q_{1}$ and $T_{1}$ changes. Further, a course of temperature changing in the $k$ point ( $k$ heating nod) is of essential importance. Dependence between temperatures $T_{1}$ and $T_{k}$ is arises from the following equation system (Moos, Vytlačil 1991):

$$
\begin{aligned}
& T_{1}=\frac{1}{\Delta}\left(\Delta_{11} \cdot Q_{1}+\Delta_{21} \cdot Q_{2}+\cdots+\Delta_{n 1} \cdot Q_{n}\right) \\
& T_{2}=\frac{1}{\Delta}\left(\Delta_{12} \cdot Q_{1}+\Delta_{22} \cdot Q_{2}+\cdots+\Delta_{n 2} \cdot Q_{n}\right) \\
& T_{k}=\frac{1}{\Delta}\left(\Delta_{1 k} \cdot Q_{1}+\Delta_{2 k} \cdot Q_{2}+\cdots+\Delta_{n k} \cdot Q_{n}\right) \\
& T_{n}=\frac{1}{\Delta}\left(\Delta_{1 n} \cdot Q_{1}+\Delta_{2 n} \cdot Q_{2}+\cdots+\Delta_{n n} \cdot Q_{n}\right)
\end{aligned}
$$

Considering the above determined conditions, only the following two adjusted equations are used:

$$
\begin{gathered}
T_{1}=\frac{1}{\Delta} \Delta_{11} \cdot Q_{1} \\
T_{k}=\frac{1}{\Delta} \Delta_{1 k} Q_{1}
\end{gathered}
$$

The impulse heating response are given as a fraction of both the equations (20a; 20b).

$$
L\{f(t)\}=\frac{T_{k}(p)}{T_{1}(p)}=\frac{\Delta_{1 k}}{\Delta_{11}}
$$


The time course of the temperature $T_{k}(t)$ in the $k$ point depend on external temperature course $T_{1}(t)$ can be determined either by means of Laplace transformation:

$$
T_{1}(t)=\mathcal{L}^{-1}\left\{\frac{\Delta_{1 k}}{\Delta_{11}} \cdot T_{1}(p)\right\}
$$

or, after substituting the Laplace operator for $p=J \omega_{i}$, by means of the Fourier transformation:

$$
T_{1}(t)=\widetilde{f^{-1}}\left\{\frac{\Delta_{1 k}}{\Delta_{11}} \cdot T\left(j \omega_{t}\right)\right\}
$$

as a sum of harmonic components from the heating Fourier spectre. (Lloyd et al., 1978)

If the $[h]$ system matrix is known then determining a time dependent temperature course in some selected heating nod is possible from the equations (20a; 20b). The $[h]$ matrix can be compiled with a help of the heating model. Such the model with concentrated elements is shown on Figure 3. The requested [ $h]$ matrix is of the table form consisting of $n$ rows and $n$ columns where the $n$ variable represents a number of the system heating nods. These heating nods are coupled through the thermal resistances $R_{t 1}, R_{t 2} \ldots$ and thermal capacities $C_{t 1}, C_{t 2}$ in the model. The main diagonal elements of the $[h]$ matrix create sums of reciprocal values of thermal resistances coupled to numerically appropriate heating nods (Evola and Marletta, 2013). The other elements are created by reciprocal values of thermal resistances with minus signs coupling individual heating nods. Since also inertial construction properties are considered in the system due to thermal capacities, the Laplace images of heating flows and temperatures fractions are added to the reciprocal values of thermal resistances in the $\mathrm{i}^{\text {th }}$ nod with the attached thermal capacity (Moos, 1989):

$$
\frac{Q_{i}(p)}{T_{i}(p)}=p C_{t i}
$$

The partial $[h]$ system matrix is of the following form (25):

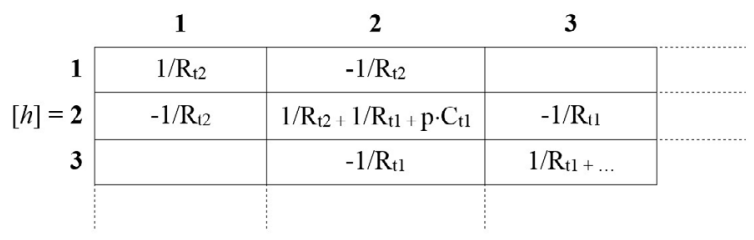

Sources of the heating flow in the $i^{\text {th }}$ nod $-Q_{\mathrm{i}}$ controlled by the temperature $T_{i}$ in the $j^{\text {th }}$ nod can be expressed by the linear equation:

$Q_{i}=g \cdot T_{j}$

where $g$ is a regulation factor - are in the $[h]$ matrix represented so that the transfer heating conductivity $g$ performing the regulation factor function is added to the element in the $i^{\text {th }}$ row and $j^{\text {th }}$ column of the $[h]$ system matrix.

Between each pair of heating nods $i$ and $j$, there is a construction element described as the system with spread parameters and, from that, a partial matrix of the second-order (its compact form in 26)

$\left[\begin{array}{l}Q_{i} \\ Q_{j}\end{array}\right]=\left[\begin{array}{ll}h_{i i} & h_{i j} \\ h_{i j} & h_{j j}\end{array}\right] \cdot\left[\begin{array}{c}T_{i} \\ T_{j}\end{array}\right]$

is derived and its partial parameters $h_{i i}, h_{i j}, h_{i j}$, and $h_{i j}$ also being functions of Laplace operator $p$ and, further, functions of the construction geometrical dimensions (wall thickness for example) are added to appropriate elements of the $[h]$ matrix.

The partial section of the construction described by the equation (27) can consist of several layers (see Fig 3). The partial layers can be suitably characterized by the following matrix equation:

$\left[\begin{array}{l}T_{1}(p) \\ Q_{1}(p)\end{array}\right]=\left[\begin{array}{cc}\cosh \gamma d & \varrho_{0} \sinh \gamma d \\ \frac{1}{\varrho_{0}} \sinh \gamma d & \cosh \gamma d\end{array}\right] \cdot\left[\begin{array}{l}T_{2}(p) \\ Q_{2}(p)\end{array}\right]$

where

$\gamma=\sqrt{p \cdot R_{i} \cdot C_{i}}$ heating constant;

$\varrho_{0}=\sqrt{\frac{R}{p C_{i}}} \quad$ specific heating constant;

$R_{i} \quad$ specific thermal resistance $\left[\mathrm{W} \cdot \mathrm{m}^{-1} \cdot \mathrm{K}^{-1}\right.$;

$\mathrm{C}_{\mathrm{i}} \quad$ specific thermal capacity $\left[\mathrm{J} \cdot \mathrm{m}^{-1} \cdot \mathrm{K}^{-1}\right]$.

The resulting function

$\left[\begin{array}{cc}\cosh \gamma d & \varrho_{0} \sinh \gamma d \\ \frac{1}{\varrho_{0}} \sqrt{p R_{i} C_{i}} & \cosh \gamma d\end{array}\right] \cdot\left[\begin{array}{cc}A & B \\ C & D\end{array}\right]$

can be obtained as a product of partial matrices (28) for separate construction layers:

$\left[\begin{array}{ll}A & B \\ C & D\end{array}\right]=\left[\begin{array}{ll}A_{1} & B_{1} \\ C_{1} & D_{1}\end{array}\right] \cdot\left[\begin{array}{ll}A_{2} & B_{2} \\ C_{2} & D_{2}\end{array}\right] \cdot\left[\begin{array}{ll}A_{3} & B_{3} \\ C_{3} & D_{3}\end{array}\right]$ 
The matrix (29) is transformed on the form compatible with the system matrix according to the following transformation function:

$$
[h]_{i j}=\frac{1}{B} \cdot\left[\begin{array}{cc}
A & -1 \\
-1 & D
\end{array}\right]
$$

The triple layer construction according to Figure 3 (lower scheme) includes the resulting thermal resistance of separate layers $\Sigma R_{p} ; i=1, \ldots, 4$ $\left(R_{1}\right.$ includes heating properties of heat transfer from exterior and $R_{4}$ heating transfer from the wall to interior) and thermal resistance of the window $R_{O}$. Further, the construction includes the resulting thermal capacities of separate layers $\Sigma C_{l}$; $i=1, \ldots, 4\left(C_{4}\right.$ represents thermal capacity of interior). The unregulated heating source heating system $W_{1}$ (cattle) supplies the interior by the heating flow $Q_{5}$ and the regulated heating source $W_{2}$ (heating system regulated by the temperature $T_{4}$ measured on the inner surface of the perimeter wall; $Q_{6}$ is equal to regulation factor $g$ ) supplies the interior by the heating flow $Q_{6}$. According to the described procedure, the following system matrix $[h]$ can be compiled (equation 32, this page below) (Moos and Vytlačil 1991):

where:

$k \quad$ sum of heat transfer coefficients $\Sigma k_{1} ; i=1$, 2, 3 of all layers;

$k_{0} \quad$ heat transfer coefficients of window.

The Laplace image of impulse characteristic is expressed as the fraction of the algebraic complements $\Delta_{11}$ and $\Delta_{15}$ (question 33 , this page below):

If the temperature $T_{1}$ suddenly decreases in the time $t=t_{0}$ by $x^{\circ} \mathrm{C}$ the change can be expressed by means of the Laplace image:

$$
T_{5}(p)=\frac{\Delta_{15}}{\Delta_{11}} \cdot \frac{X}{p}
$$

so that the temperature course $T_{5}$ within the interior can be computed by the help of the reversal Laplace transformation of the following equation:

$T_{1}(t)=\mathcal{L}^{-1}\left\{\frac{\Delta_{15}}{\Delta_{11}} \cdot \frac{X}{p}\right\}$

The course of the temperature response is shown in the Figure 4.

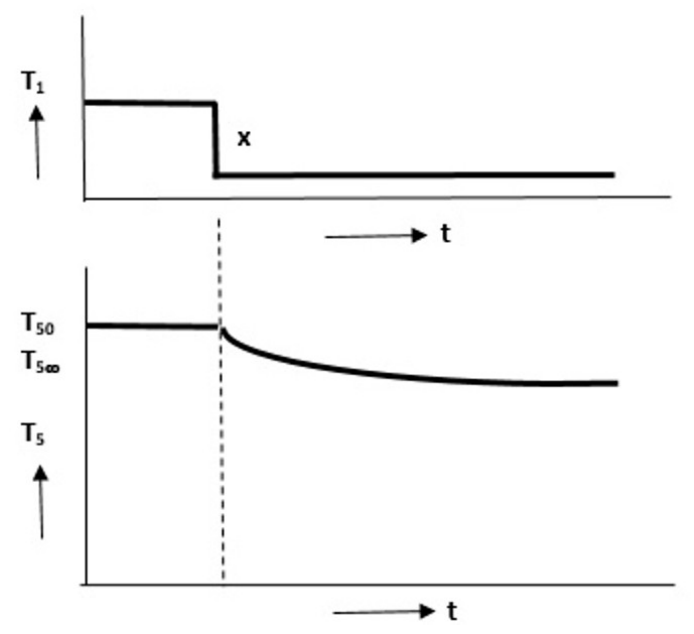

Source:

Figure 4:Time characteristics of temperature changes.

\section{Results and discussion}

Analysis of computed outputs

For analysis, the barn whose construction heating scheme is shown on Fig. 3 was used. As input data, the following set of input information was entered (Veverka et al., 1992):

- exterior temperature values was adopted from the temperature standard for a clear winter day (Figure 5).

- $\quad$ thermal resistances of individual materials $R_{i}$ $\left[\mathrm{W} \cdot \mathrm{m}^{-1} \cdot \mathrm{K}^{-1}\right]$ (see Table 1);

- thermal capacities of individual materials $C_{i}$ $\left[J \cdot m^{-1} \cdot K^{-1}\right]$ (see Table 1$)$;

$$
\begin{aligned}
& {[h]=\left[\begin{array}{ccccc}
k+k_{0} & -k_{1} & -k_{2} & -k_{3} & -k_{0} \\
-k_{1} & k+1 / R_{1}+p \cdot C_{1} & -1 / R_{2} & -1 / R_{3} & -1 / R_{4} \\
-k_{2} & -1 / R_{1} & k+1 / R_{2}+p \cdot C_{2} & -1 / R_{3} & -1 / R_{4} \\
-k_{3} & -1 / R_{1} & -1 / R_{2} & k+1 / R_{13}+p \cdot C_{3} & g-1 / R_{4} \\
-k_{0} & -1 / R_{1} & -1 / R_{2} & g-1 / R_{3} & k_{0}+1 / R_{4}+p \cdot C_{4}
\end{array}\right]} \\
& \frac{T_{5}}{T_{1}}=\frac{\Delta_{15}}{\Delta_{11}}=\frac{\frac{k_{0}}{C_{4}} \cdot\left[\frac{k}{k_{0} C_{1}} \cdot\left(1 / R_{4}-g\right)+\frac{k+1 / R_{4}}{C_{4}}+p\right]}{p^{2}+p+\left(\frac{k_{0}+1 / R_{4}}{C_{4}}+\frac{k_{0}+1 / R_{4}}{C_{1}}\right)+\frac{1 / R_{4} \cdot g+k \cdot k_{0}+1 / R_{4} \cdot k+1 / R_{4} \cdot k_{0}}{C_{1} \cdot C_{4}}}
\end{aligned}
$$




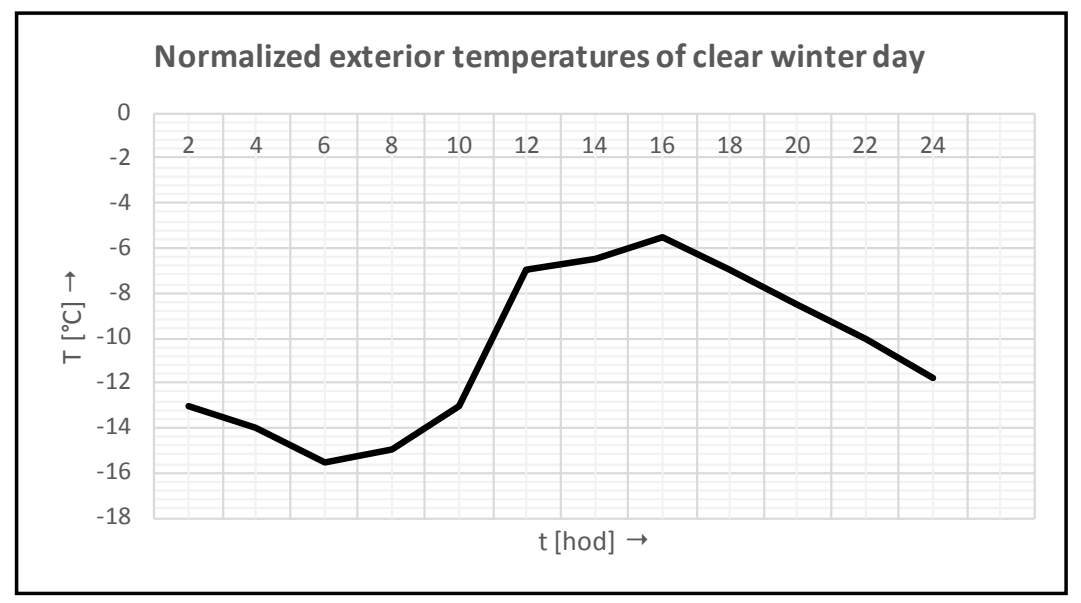

Source:

Figure 5: Normalized exterior temperatures of clear winter day.

\begin{tabular}{|c|c|c|c|}
\hline Material & Thickness [m] & $\begin{array}{c}\text { Thermal resistance } \\
\mathbf{R}_{\mathrm{i}}\left[\mathbf{W} \cdot \mathbf{m}^{-1} \cdot \mathbf{K}^{-1}\right]\end{array}$ & $\begin{array}{c}\text { Thermal capacity } \\
C_{\mathrm{i}}\left[\mathrm{J} \cdot \mathrm{m}^{-1} \cdot \mathrm{K}^{-1}\right]\end{array}$ \\
\hline \multicolumn{4}{|c|}{ A) Reinforced concrete cladding } \\
\hline Reinforced concrete & 0.225 & 0.059 & 840 \\
\hline Polystyrene & 0.145 & 2.5 & 1550 \\
\hline Heraklit & 0.115 & 0.357 & 1590 \\
\hline \multicolumn{4}{|l|}{ B) Ceramic cladding } \\
\hline CD-IVA-C & 0.14 & 0.238 & 690 \\
\hline Polystyrene & 0.04 & 2.5 & 1550 \\
\hline CD-IVA-C & 0.14 & 0.238 & 690 \\
\hline \multicolumn{4}{|c|}{ C) Plasterboard cladding (no supporting structure; used with any other construction) } \\
\hline Plasterboard & 0.03 & 0.625 & 1380 \\
\hline Prefizol & 0.10 & 2.0 & 920 \\
\hline Eternit boards & 0.02 & 0.2 & 960 \\
\hline
\end{tabular}

Source: Rochla (1983)

Table 1: Cladding configurations.

- thermal resistances of window $R_{i}$ $\left[0.04 \mathrm{~W} \cdot \mathrm{m}^{-1} \cdot \mathrm{K}^{-1}\right]$;

- unregulated heating source $W_{1}$ [cattle; constant 125 W.K ${ }^{-1}$;

- regulated heating source $\mathrm{W}_{2}$ [heating system; constant 100 W.K ${ }^{-1}$;

Processing the input data using ANATH application is carried out in several steps:

1) Fourier transformation of temperature time course being an independent variable causing temperature changes within the construction.

2) Assigning numbers to individual points - or heating nods - within and out of the construction whose temperature should be examined.

3) Creating a heating model of the building construction and its couplings to the examined object within the building's interior.
4) Forming a matrix of heat penetration and heating absorbability through given parts of the construction. Completing the elements representing the heating system and adding the submatrices characterizing the system with spread parameters. The result is the system matrix.

5) Obtaining the image of the system's heat impulse responses in the nods important from the viewpoint of heating gradients by the help of quotients of the system matrix algebraic complements and optimizing the function of the heating system.

6) Determining the temperature course in the examined points by reverse transformation of the Fourier convolution image of exterior temperature time course with the system impulse response (Moos and Vytlačil 1991). 
The resulting graphs consist of two parts. The first ones (situated in upper halves) represent rough (continuous lines) curves (according to Figures 6-8) and smooth interpolated (dashed lines) curves of exterior temperatures. The second ones (situated in lower halves) represent responses of interior temperature on the exterior temperatures shown above.

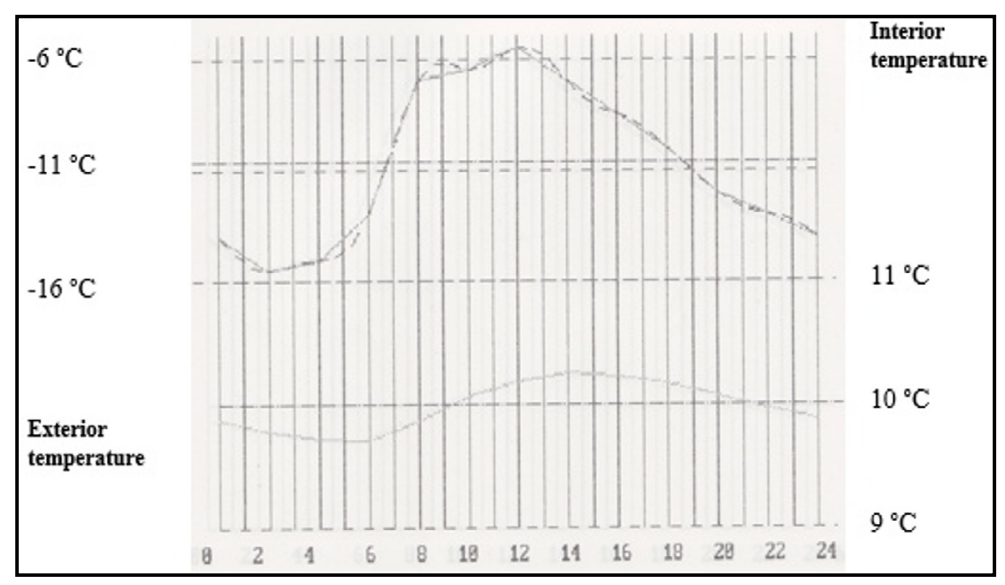

Source: authors' own processing in ANATH

Figure 6: Heating responses of Cladding A.

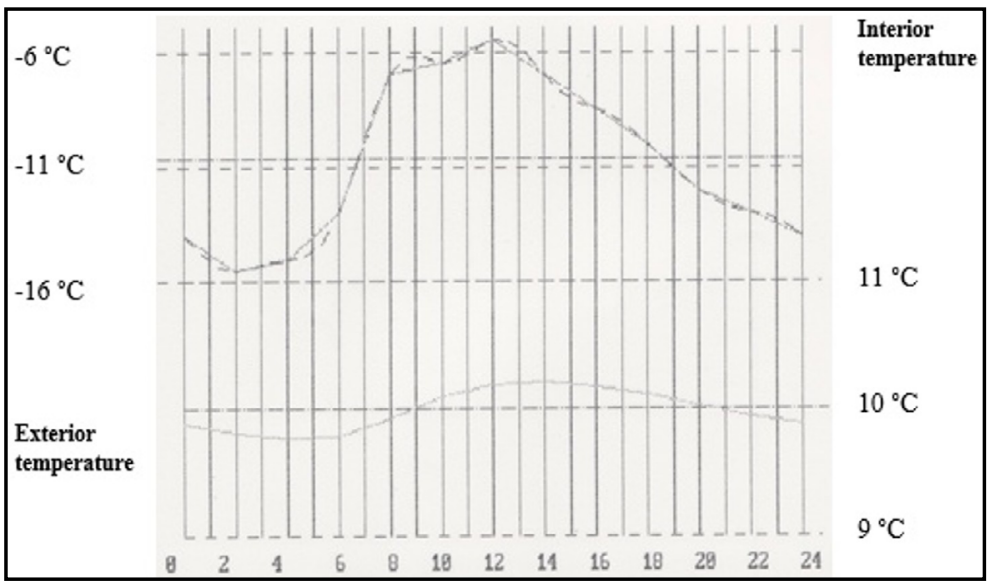

Source: authors' own processing in ANATH

Figure 6: Heating responses of Cladding B.

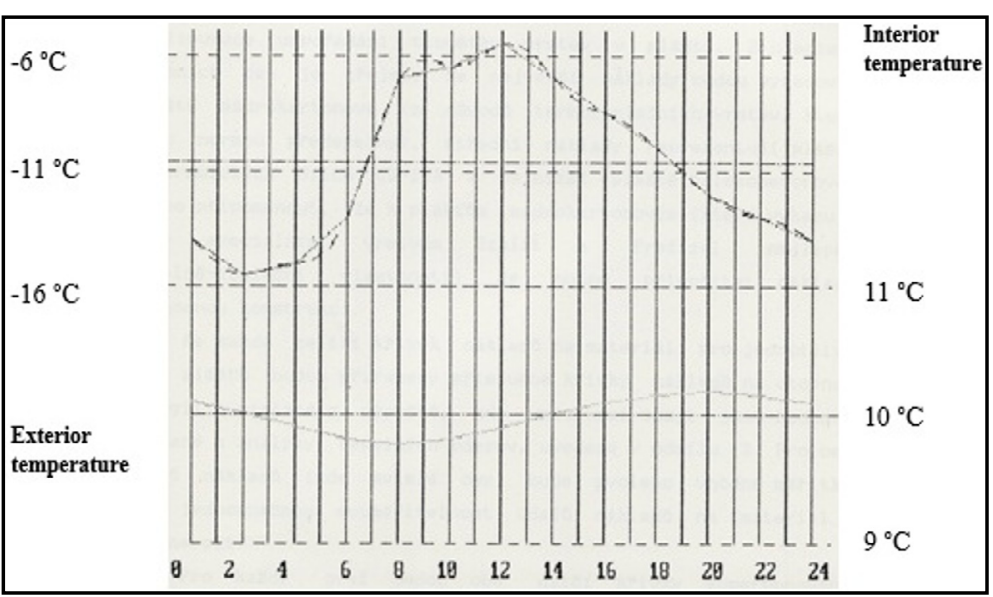

Source: authors' own processing in ANATH

Figure 6: Heating responses of Cladding C. 


\section{Conclusion}

Knowledge of time temperature characteristics enables expecting values of mechanical tension inside constructions given by thermal dilatations of structural parts in the course of non-stationary thermal processes and, afterwards, building construction optimizing. The complex analysis of temperature time characteristics can be applied for examining thermal bridges within interiors of building objects with humid ambient and with light cladding (Cooke 1975). The results provided in the form of graphs and temperature data files by the ANATH application can be used by various manners. For example, they can serve for simulating inner temperatures of agricultural buildings (cow barn, in our case) and following setting the appropriate heating plan via programming heat regulation systems - provided the existing building objects or for designing optimal construction configuration (system of cladding layers arrangement) in case of planned objects (Hoffman and Feldman, 1981). A specific task was solved by Malinovský in 1993, when a cost curve (material costs versus heating costs) had been built on the basis of analysing heating responses at different cladding material configurations an standardized exterior temperatures. Of course, analysing thermal behaviour of building object interiors on the basis of multi-factors (temperature responses, cladding material configuration, heating system configuration, construction type, ventilation system and mode, etc.) can be used for lot of different purposes in the field agriculture engineering.

Corresponding authors:

Ing. Vit Malinovský, Ph.D.

Department of System Engineering, Faculty of Economics and Management

Czech University of Life Sciences Prague, Kamýcká 129, 16500 Praha-Suchdol, Czech Republic

Phone: +420606482 119,E-mail:vit.malinovsky@volny.cz, malinovskyv@pef.czu.cz

\section{References}

[1] Bracewell, R. (1999) “The Fourier Transform and Its Applications", McGraw-Hill, New York, USA. ISBN 978-00-730-3938-1.

[2] Chloupek, J. (2012) “Posuzování tepelné bilance a větrání stájových objektů pro hospodářská zvířata, multimediální učební text” (in Czech), University of Veterinary and Pharmaceutical Sciences Brno, Brno.

[3] Cooke, J., Robert, J. and DeBaerdemaeker, J. G. (1975) “Transient Thermal Behavior of Agricultural Buildings, Including Subsurface Heating”, Paper - American Society of Agricultural Engineers.

[4] Dong, Z., Zhu, P., Bobker, M. and Ascazubi, M. (2015) "Simplified characterization of building thermal response rates", Energy Procedia, Vol. 78, pp. 788-793. ISSN 1876-6102. DOI 10.1016/j.egypro.2015.11.098.

[5] Draghici, F., Mitu, F., Dilimot, G. and Enache, I. (1998) "Method to increase the thermal stability of the heating circuits“, Proceedings of the International Semiconductor Conference, CAS 2, pp. 501-504.

[6] Evola, G. and Marletta, L. (2013) "A dynamic parameter to describe the thermal response of buildings to radiant heat gains", Energy and Buildings, Vol. 65, pp. 448-457. ISSN 0378-7788. 10.1016/j.enbuild.2013.06.026.

[7] Hoffman, M. E. and Feldman, M. (1981) "Calculation of the thermal response of buildings by the total thermal time constant method", Building and Environment, Vol. 16, No. 2, pp. 71-85. ISSN 0360-1323. DOI 10.1016/0360-1323(81)90023-8.

[8] Jok1, M. (1989) “TZB - technická zařízení budov II: Interní mikroklima, ventilační a klimatizační technika pro stavební inženýry” (in Czech), Czech Technical University in Prague.

[9] Lloyd, J. R. and Davisson, M. C. (1978) "Simulation of the Thermal Response of Buildings to Changes in the Environment", Modeling and Simulation, Proceedings of the Annual Pittsburgh Conference, 9 (pts 1-4), pp. 295-300. 
[10] Malinovský, V. (1989) "Systémový makromodel pro analýzu spotřeby energie s ohledem na její minimalizaci" (in Czech), diploma thesis, Czech Technical University in Prague. ISBN 978-80-010-0081-6.

[11] Mehta, D. P. and Woods, J. E. (1981) "Accuracy of an Analytical Model to Predict Dynamic Thermal Responses of Building Systems", Proceedings of the National Conference on Power Transmission, pp. 457-469.

[12] Moos, P. (1989) "Počítačový makromodel tepelného mikroklimatu budov" (in Czech), Pozemní stavby, Vol. 2, pp. 92-96.

[13] Moos, P. and Vytlačil, D. (1991) "Citlivosti přenosu tepla na parametry stavebních konstrukcí” (in Czech), Energetika, Vol. 2, pp. 45-49. ISSN 0375-8842.

[14] Moziraji, Z. P., Azimi, A. and Hannani, S. K. (2014) “Analysis and modeling of building thermal response to investigate the effect of boundary conditions", Scientia Iranica, Vol. 20, No. 4, pp. 1269-1277. E-ISSN 2345-3605, ISSN 1026-3098.

[15] Pöttgen, P., Ederer, T., Altherr, L., Lorenz, U. and Pelz, P. F. (2016) "Examination and Optimization of a Heating Circuit for Energy-Efficient Buildings", Energy Technology, Vol. 4, No. 1, pp. 136-144. E-ISSN 2194-4296. DOI 10.1002/ente.201500252.

[16] Price, B. A. and Smith, T. F. (1995) "Thermal response of composite building envelopes accounting for thermal radiation”, Energy Conversion and Management, Vol. 36, No. 1, pp. $23-33$. ISSN 0196-8904. DOI 10.1016/0196-8904(94)00037-Z.

[17] Rochla. M. (1983) "Stavební tabulky" (in Czech), SNTL-Alfa, Prague.

[18] Sangi, R., Baranski, M., Oltmanns, J., Streblow, R. and Müller, D. (2016) "Modeling and simulation of the heating circuit of a multi-functional building", Energy and Buildings, Vol. 110, pp. 13-22. ISSN 0378-7788. DOI 10.1016/j.enbuild.2015.10.027.

[19] Sonderegger, R. C. (1977) "Harmonic analysis of building thermal response applied to the optimal location of insulation within the walls", Energy and Buildings, Vol. 1, No. 2, pp. 131-140. ISSN 0378-7788. DOI 10.1016/0378-7788(77)90025-1.

[20] Stupka, R., Líkař, K., Šprysl, M. and Čítek, J. (2014) “Řízení mikroklima v chovu prasat” (in Czech), FAFNR, Czech Universioty of Life Sciences Prague, Prague. ISBN 978-80-213-2401-5.

[21] Svoboda, J. (2012) "Mikroklima budov ve vztahu k energetické náročnosti” (in Czech), FA, Czech University of Technology Brno, Brno. ISBN 978-80-214-4463-8.

[22] Veverka, J., Chybík, J. and Sedlák R. (1992) “Energetické hodnocení budov a tepelná pohoda vnitřního prostředí” (in Czech), University of Technology Brno, Brno.

[23] Wachowicz, E., Raczek, A. and Woroncow, L. (2016) "The use of optimization of energy-saving microclimate control in selected agricultural objects", Journal of Research and Applications in Agricultural Engineering, Vol. 61, No. 1, pp. 119-123, Industrial Institute of Agricultural Engineering. ISSN ISSN 1642-686X.

[24] Zajicek, M. and Kic, P. (2014) "Heating of large agricultural and industrial buildings", Agronomy Research, Vol. 12, No. 1, pp. 237-244. ISSN 1406-894X. 